\title{
The umbrella's spokes are broken and the safety net has holes
}

$\mathbf{W}$ e have been assured by presidential announcement over the past several years that our society was providing very well for the disadvantaged and underserved among whom are numbered the handicapped. We are told of umbrellas and safety nets that provide this coverage. Even the most optimistic, however, recognize that government cannot solve all of the problems.

Critics have looked about and pointed out some obvious discrepancies. Television documentaries shock us with the plight of the homeless whose numbers are increasing. The spread of AIDS and its ripple effect has resulted in tremendous suffering and expense with no end in sight. The economic depression has drastically reduced most state revenues prompting double digit budget reductions. These unfortunately seem to affect most heavily services provided for the poor and those traditionally considered handicapped. Unemployment has increased further and many state and municipal services are being reduced or eliminated.

Institutions of higher learning, the often disparaged "ivory towers," are not immune. University hospitals and health care facilities are besieged with increasing numbers of patients with decreasing abilities to pay-for example, Medicare fees have been reduced by $13 \%$ in Michigan. Hard-eyed administrators push for continuous increases in productivity and efficiency. Pressures build on the system, human needs are increased, and resources become depleted. The combination of time consuming, difficult-tomanage patients, and few financial resources, strains those individuals and institutions willing to accept them. One wonders if anything good can be accomplished and if further efforts will be in vain, considering what needs to be done. The system does not seem to be working.

Perhaps we should stop treating such patients, but how can we? Let's take stock-gains have been made. Shall we lose them? Individuals with special needs who, a few years ago, might not have received any dental services can now locate some resource skilled enough and willing enough to provide coverage even at an economic loss. Granted, locating such services may take some effort. Society is much more aware of people who have special problems and needs. Most dental schools contain some elements of special patient care within their curricula and recent graduates are more inclined to accept patients with special needs. So now is not the time to say "I'm outa here," but rather to mend the net and tape the spoke as best we can.

What's to be done? For starters, let each individual and each agency take a deep breath and continue. Let's not look for places or people on which to unload. The demands on certain individuals and agencies would be lessened if spread across dentistry more uniformly. Let us continue to seek more equitable remuneration from the legislators and keep society aware of our patients' special needs. As members of a profession in the healing arts, we must continue our commitment. I don't think we have another choice.

\section{Henry Kanar, DDS}

Dr. Kanar is associate professor of dentistry, University of Michigan, Ann Arbor 48109-1078. 